\title{
Design of Internal Control System of Cost
}

\author{
Fu Minhang \\ Changping Huilongguan Beinonglu 2th North China Electric Power University,China
}

18811356399@163.com

\begin{abstract}
Along with the prosperity of the market economy, enterprises become more and more concerned about cost in the process of continuous pursuit of interests. Consequently, the internal control of cost gets particularly important. For this reason, the state has also issued a draft for internal control of the cost in order to regulate this. The design of the internal control system is elaborated from two aspects of internal management control and internal accounting control of cost in this paper.
\end{abstract}

Keywords: internal control; cost

\section{Introduction}

Under the conditions of market economy, as an independent commodity producer and operator, the purpose of the enterprise is not only to provide social needs of the product, but also to obtain economic benefits. With the end of the market shortage economy, the price competition between enterprises is increasing day by day. Many enterprises have put forward the strategic guiding ideology of "lower the price for market share." The key to ensuring the implementation of the policy of "lower the price for market share" is to reduce the cost of enterprises. If they do not reduce their cost and blindly lower price for market share, they will eventually lose everything and be out of the market. In this paper, two aspects of internal management control and internal accounting control of cost are analyzed.

\section{Organization of the Text}

\subsection{Internal management control of cost}

\subsubsection{Establish internal supervision}

The establishment of a sound cost control system should meet the requirements of improving the corporate governance structure. Restructured enterprises set up the board of directors, the board of supervisors and the shareholders' congress. In the production and operation of enterprises, important matters must be approved and reviewed by the board of directors and the board of supervisors. Moreover, they can be also approved by the shareholders' congress when it is necessary. General matters should be discussed and reviewed by the administrative leaders in order to strengthen the internal supervision.

The main contents of cost supervision and inspection:

1. Cost business related positions and personnel settings. Whether incompatible positions of cost business are mixed shall be the focus of inspection.

2. Implementation of cost business authorization system. Whether the cost authorization system is sound and whether there is ultra vires act are the focuses of the inspection. 
3. mplementation of cost budget system. Whether the authenticity, reasonableness and legality of the cost exceed the scope of the budget is the focuses of the inspection.

\subsection{Set up authorization control}

Personnel at all levels of the enterprise should reasonably and effectively assign the responsibility and authority of the internal activities of the organization. Unauthorized personnel are not allowed to contact and control the business. Authorization control system uses the system to regulate executives at all levels to carry out the work as soon as possible without instructions in order to avoid the phenomenon of work prevarication within their scope of responsibilities and business processing authority. Furthermore, it defines the responsibilities of each authorized personnel, so that they are responsible for their business handling behavior, thereby strengthening the sense of responsibility.

Authorization can be divided into general authorization and special authorization in accordance with its form. The so-called general authorization refers to the provisions of the power, conditions and responsibilities to handle routine business, and generally its timeliness is longer. While special authorization is the provisions of authority, conditions and liabilities to hand exceptional business. Generally its timeliness is shorter. No matter which way of authorization is adopted, the enterprise must establish an authorization system, and it includes: 1.Scope of authorization. 2. Authorization level. Different levels of authorization should be determined based on the size and importance of the amount of economic activity so as to ensure that the management team has the authority and responsibility. 3. Responsibility for authorization. The responsibility of the authorized person to perform his powers shall be clearly defined.

\subsection{Establish post division control}

Units shall establish the post responsibility system of cost business; clarify the duties and authority of the relevant departments and posts, and ensure that the incompatible positions of the cost business shall be separated, restricted and supervised. The so-called incompatible duties refer to those positions which are served by a person who may have mistakes and drawbacks and can cover up their mistakes and shortcomings.

Cost incompatible positions include at least: 1, Preparation and approval of cost budget; 2, Approval and execution of cost expenditure. 3. Implementation of cost expenditure and related accounting records. Specifically, it requires the mutual separation, mutual restraint and mutual supervision between the various positions so as to ultimately reduce the possibility of errors and fraud, thereby fully embodying the nature of internal accounting control.

\section{Internal accounting control of cost}

\subsection{The establishment and improvement of internal accounting control are a systematic project,} which can be considered from three aspects of pre-control, in-process control and post-control.

\subsubsection{Pre-control}

It is mainly to establish a strict cost budget system, and the cost budget should be consistent with the unit's development goals and cost-effective principles. Units shall decompose the cost index according to the cost budget content. In general, the function of the product determines the structure of the product, the number of parts, the type of material and consumption quota, product manufacturing process, etc, so the product function largely determines the product cost level. Therefore, it is necessary to analyze the needs of different customer groups, and then produce products that match the functionality.

\subsubsection{In-process control}

It refers to the daily cost control in the process of cost formation. At this stage, actual costs incurred are usually 
controlled, directed and supervised in order to ensure that the original cost target is achieved. I think the best way to carry out the in-process control is to establish a standard cost system, i.e., a predetermined cost that is used to evaluate actual costs and to measure work efficiency through precise investigation, analysis, and technical determination. In the standard cost, basically unnecessary "wastes" are ruled out. Therefore, it is considered to be a "necessary cost": The usual metrics are as follows:

(1) Cost standard (Unit product standard cost) $=$ Unit product standard consumption $\times$ Standard unit price

(2) Standard cost $=$ Actual output $\times$ Cost standard

\subsubsection{Post-control}

Post- control is not only a summary of cost control after an accounting period, but also the beginning of cost control in the next accounting period. Post-control helps to find out which measures are effective in this workflow, , which measures exist deficiencies, so as to summarize the lessons of the next work process, and put forward more effective measures and methods.

\subsection{Cost business flow and corresponding control measures}

\subsubsection{Cost business process flow is generally}

(1) Develop the cost standard; (2) Work out the plan; (3) Picking; (4) Record working hours and output; (5) Record power consumption; (6) Collect documents; (7) Review; (8) Determine the ownership period; (9)Determine the cost bearer; (10)Inventory; (11)Calculate the reasonable allocation of product cost between finished products and unfinished products; (12) Bookkeeping;

(13) Make the report

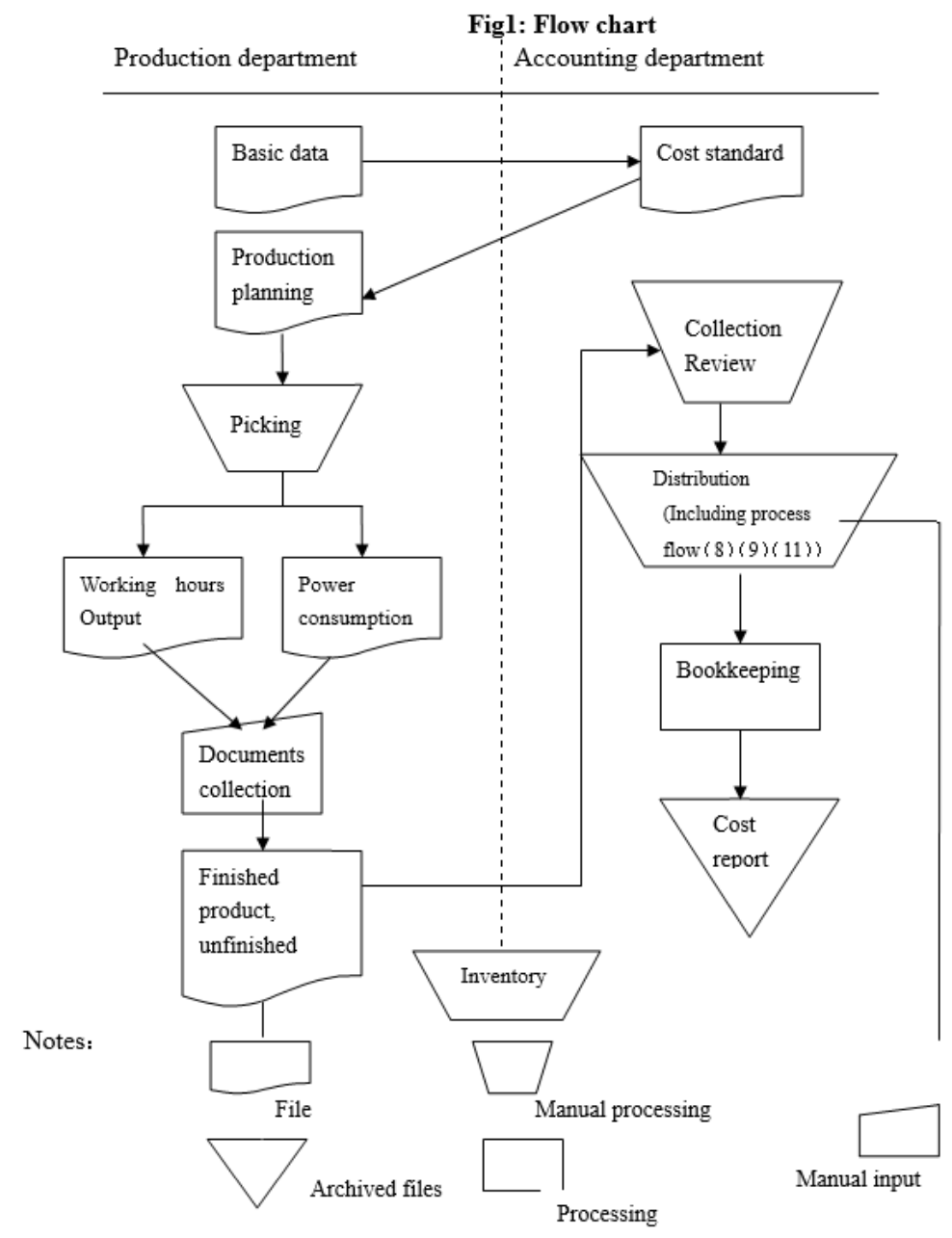




\subsubsection{Cost control points and control measures:}

\subsubsection{Examination and approval}

Special personnel fill in relevant documents of expenses required by each workshop and functional department and then they will be reviewed and approved by the responsible personnel of the workshop or department. Expenses exceeding the quota or budget shall be reviewed and approved by the superior.

\subsubsection{Issuance}

The warehouse keeper checks whether the number of approved requisitions of the material exceeds the limit, whether procedures are complete, and then signs on the material document and issues the materials according to this. The labor department checks original records such as work records and production record that transferred from workshop and other functional departments, and then issues the payroll statement provided by the accounting department. The accounting department examines whether various comprehensive expenses paid in monetary capital exceed the budget, whether the formalities are complete, and then handles the settlement of monetary capital.

\subsubsection{Review}

The relevant personnel of the accounting department shall respectively examine the completeness of the original vouchers for various expenses and basic contents of transfer voucher transferred from procurement, labor and other departments; handle the completeness of the formalities and the legality of the economic content, calculate the correctness of the content, and then sign and seal the document for approval.

\subsubsection{Bookkeeping}

The chief accountant of production cost breakdown registers the itemized account according to the original document and accounting vouchers. After the registration is completed, the chief accountant checks the amount of its original vouchers or accounting vouchers with the total amount, and then sign and seal to indicate the completion of the registration.

\subsubsection{Classification}

The accounting personnel classify and divide the expenses that should be included in the product cost according to vouchers for distributing and returning materials after the review, and original vouchers for payroll settlement and other expenses, and then make the summary and allocation sheet table for all costs on the basis of the project.

\subsubsection{Inventory}

The accounting department and production department will regularly check unfinished products, verify the number of unfinished products, determine the degree of completion of the unfinished product, handle the shortage and overage and scrapped products, and then make the product inventory table.

\subsubsection{Distribution}

Cost accounting personnel of the accounting department allocate the production cost that has occurred and should be classified as product costs in each period, various products as well as finished products and products according to the production cost summary and allocation table, and product inventory table, and then calculate the cost and unit cost of the finished product and make the product costing sheet.

\subsubsection{Double-check}

After the product cost is calculated, the accounting department supervisor checks whether the cost accounting method is appropriate, whether the allocation method and allocation ratio are reasonable, 
whether the accounting procedures are compliance, and whether the calculation results are correct. After everything is correct, they sign on the document for approval.

\subsubsection{Carry-over}

The chief accountant of the accounting department makes the product cost summary, fills in relevant vouchers, timely carries over the cost of the product according to the reviewed product costing sheet, and then make the cost report according to the product costing sheet and the balance of related subjects.

\subsubsection{Account checking}

Under the supervision of the audit staff, the chief accountant of production cost breakdown and the accountant of production cost ledger carry out the reconciliations on amount and balance of the ledger of production breakdown and production cost ledger, they get signed to show the reconciliation.

\subsubsection{Review and signature}

The accounting supervisor checks the cost reporting data to ensure that the ledger is in conformity with other tables and affixes the signature after everything is right; and then sends the documents to the responsible person of the enterprise for approval and sampling.

\section{Conclusions}

In short, the design of internal control of cost is a systematic project, which requires managers to conduct a full range of analysis and consideration so as to deeply realize the great significance of cost to enterprise's considerable development.

1 Strengthening the internal control of cost is an important part of corporate governance, which is a powerful guarantee for improving management, anti-counterfeiting checks, plugging loopholes and protecting property.

2 Strengthening internal control of cost needs to look for the control point and take corresponding control measures in the process of studying the cost business process, and this is a very important basic work.

3 The key to strengthening the content of internal control of cost is to ensure the reasonable setting and reasonable division of duties and powers of institutions and positions within the unit involving accounting, especially the mutual separation, mutual restraint and mutual supervision of incompatible duties.

\section{Acknowledgement}

Finally, it is worth mentioning that even if the internal control system is perfect, it still needs to be fully implemented. Therefore, it is necessary to establish a set of feasible reward and punishment assessment methods, clearly stipulate various assessment indicators and methods, decompose and implement the cost index layer by layer, so that the cost index can be truly linked to the vital interests of the employees, and reward and punishment measures can be carried out in order to ultimately reduce the cost and improve the economic efficiency of enterprises so as to ensure the further development. 


\section{References:}

[1]Fan Hangjian, A Study on Internal Accounting Control of Cost, Contemporary Finance \& Accounting, 2002,7.

[2]Hu Jianwen, On the Construction of Enterprise Internal Control System, Communication of Finance \& Accounting, 2003,12.

[3]Xu Guoqiang, Song Hongjuan, Assumption of Formulating Cost Accounting Standard in Chinese Enterprises, Communication of Finance \& Accounting, 2003,6.

[4]Dong Linhong, Li Jian, Analysis of Internal Control of Cost, Shanxi Finance and Tax, 2003,5.

[5]Kang Baocheng, Reflections on Internal Control of Enterprises, Research of Finance and Accounting, 2004,4.

[6]Han Guohua, Enterprise Internal Control System Design, Research of Finance and Accounting, 2003,8 .

[7]Liu Minghui, Audit, Dalian, Dongbei University of Finance and Economics Press, 2004

[8]Office of Certified Public Accountants Examination Committee, Audit, Beijing, China Financial and Economic Publishing House, 2005

[9]Internal Accounting Control Norms - Cost (Draft for comment), China Finance and Accounting Network.

[10]Xu Zhenjing, Zhang Jianping, Strengthen Cost Control and Improve Enterprise Competitiveness, Zhongzhou Audit, 2001,9. 